\title{
The Impact of E-Hailing Competition on the Urban Taxi Ecosystem and Governance Strategy from a Rent-Seeking Perspective: The China E-Hailing Platform
}

\author{
Lei Ma ${ }^{1}$, Tao $\mathrm{Li}^{1}{ }^{1} * \mathbb{1}$, Jinxi $\mathrm{Wu}^{2}$ and Dandan Yan $^{1}$ \\ 1 School of Intellectual property, Nanjing University of Science and Technology, Nanjing 210094, China; \\ 12009040@njust.edu.cn (L.M.); dandanlo7179@163.com (D.Y.) \\ 2 School of Social Sciences, Tsinghua University, Beijing 100084, China; wujx02@tsinghua.edu.cn \\ * Correspondence: dogfaraway@163.sufe.edu.cn; Tel.: +86-137-0162-8855
}

Received: 8 June 2018; Accepted: 7 August 2018; Published: 9 August 2018

\begin{abstract}
Nowadays, the way of Internet travel in China presents diversified development. Rapid expansion in the personal mobile terminal and Internet infrastructure for the Internet travels to the ecosystem of development and evolution. This paper explores the influence of the expansion of the e-hailing ecological community on the urban taxi ecological community, and the problems of profit-seeking, rent-setting, and rent-seeking from the capital behind the e-hailing platform. With entrance into the urban travel ecosystem with ride-hailing platform enterprises and emerging business models, how does (venture) capital cause the change of the urban taxi ecology? Is it essentially the rent-setting and rent-seeking behavior of capital that obtains the market monopoly status of e-hailing? What are the difficulties for governments and the public in regulating rent-seeking in capital and emerging business models? The aim is to explore the new governing strategy of urban taxi ecology. The paper chooses the case of the DiDi e-hailing platform, and performs a study on the utility and indifference curves quantitatively, and constructs a rent-seeking liaison between platform's entry into the market and the platform's monopoly. In this paper, the ecological system of the taxi industry is first sorted out, and the community relationship between the traditional cruise taxi industry and the e-hailing industry, and their market supply and demand relationship are clarified. Secondly, from the main theoretical perspective of rent-seeking behavior, this paper analyzes the causes of the rent-setting rent-seeking behavior of e-hailing platform enterprises and the venture capital behind them, and the problems of public power supervision. As the red pack \& subsidy market strategy changes the utility (indifference) curve of passengers, the consumption preference of passengers is more inclined to e-hailing. With the expansion of the e-hailing community, the e-hailing platform partly replaces the regulatory role of the government, and venture capital investors as rational-economic individuals, and its agency responsibilities and profit-seeking characteristics naturally form a contradictory pair. The introduction of competition is a means among market policies to break monopoly. Even so, commercial competitors are able to avoid laws or regulations by the means of commercial mergers or through the implementation of variable interest entities control. Governments should therefore seek to participate actively in the governance of such organizations.
\end{abstract}

Keywords: sharing economy; venture capital; e-hailing; rent-seeking; public power

\section{Introduction}

Nowadays, China's Internet-based travel is developing in a diversified way. The rapid popularization of personal mobile terminals and Internet infrastructure enables the development and 
evolution of urban travel ecosystems. Via the Internet, travel tools provide real-time and customized services, and encourage the public to experience a new way of taking taxis. Increasing convenience has come into the public's daily life. With the help of the Internet platform, the public is not only the demander, but also the supplier to join the traditional cruise taxis. However, the issue of the e-hailing license legalizes the public to be e-hailing drivers as a supply source. More and more illegal car-hailing drivers are choosing e-hailing platforms to offer services legally and to earn money. Open innovation benefits a sharing economy. The practice of a sharing economy in China stems from the spirit of trust, and of open data by governments and enterprises. It is in line with the strategy of promoting economic growth with the "double engine" of "Mass Entrepreneurship and Innovation" national strategy. Yun studies the dynamics of Open Innovation Ecology System's (abbreviated OIES) open innovation economy and answers the question of economic growth after the capital economy, suggesting that it is necessary to introduce a combination of technology, market and social structure to Small \& Medium-sized Enterprises (abbreviated SMEs), start-ups, and innovative economic development in an open innovation economy [1], which meets the situation of platform enterprises entering into an e-hailing market that combines the Internet of Things (IoT) and Big Data technologies, and that brings a new era of urban taxi economy. Yun, Won, and Park establish conceptual models for the analysis and prediction of the dynamic effects of open innovation [2]. Yun also found proofs of economy of diversity in the economic characteristics of open innovation [3]. Open innovation in urban taxi market was first granted by the government, which brought competition to traditional cruising taxis, and squeezed illegal taxis out of the market. The complex and various dynamics in the relationship between open innovation and business performance are revealed by Yun's research via a game of life simulation, a mathematical modeling simulation, and causal loop modeling [4]. Hence, Open Innovation promotes the healthy development of business ecology. Yun et al. conclude that platform businesses change the sectorial innovation system, based on the study of the Apple \& Android software industry, and the hotel industry of Daegu [5]. The impact of open innovation on business performance is very dynamic, and appears in unpredictable forms [4]. Open Innovation policy plays a key role in the regional economy, both in the short run and in the long run. By using a causal loop simulation, Yun et al. revealed and established the effects of Open Innovation policies on the National Innovation Society [6]. It is able to be reasonable and rational to extrapolate from the case study of Cambodia in Yun's research that the mixed level of Open Innovation Polices can result in competitiveness of multi-time-spans in a country that implements different level of Open Innovation (abbreviated OI) policies by regional, especially proofs found in developing countries as Eastern Europe and regional characteristics in China. Digging one level deep down into a country-level or regional OI, the Open business model (OBM) in a platform enterprise changes dynamically, as proven by Yun's study that a single business can develop a business model into several platforms [5], hence, the change in forms. This study tries to go an extra mile to explain the reason for the different focus on utilities from the supply side and demand side in China's e-hailing platform, which causes governance problems in monitoring platform enterprises with a rent-seeking perspective.

\section{Ecology of Urban Taxi}

According to Encyclopedia Britannica, a city is "relatively permanent and highly organized center of population ..." [7]. The taxicab is a "chauffeur-driven automobile available for hire to carry passengers between any two points within a city or its suburbs for a fare determined by a meter or zone system or a flat rate" [8]. E-hailing (hereinafter referred to as car-hailing) is engaged by urban residents that provide driving services, and that form employment relations with passengers who have a definite destination, and the service is priced according to a unified rate system.

The ecological circle of the urban taxi is divided by the role of participating groups (Figure 1):

Car supplier-traditional cruise taxis, illegal taxis, e-hailing cars;

Car demander-Urban citizens;

Regulators-Government agencies, associations, and mainstream media; 
Platforms-Internet enterprises that provide vehicle information exchange;

Material manufacturer-Vehicle manufacturers, mobile devices, and IoT manufacturers;

Big Data Infra-structure constructor-Mobile operators i.e., China Telecom.

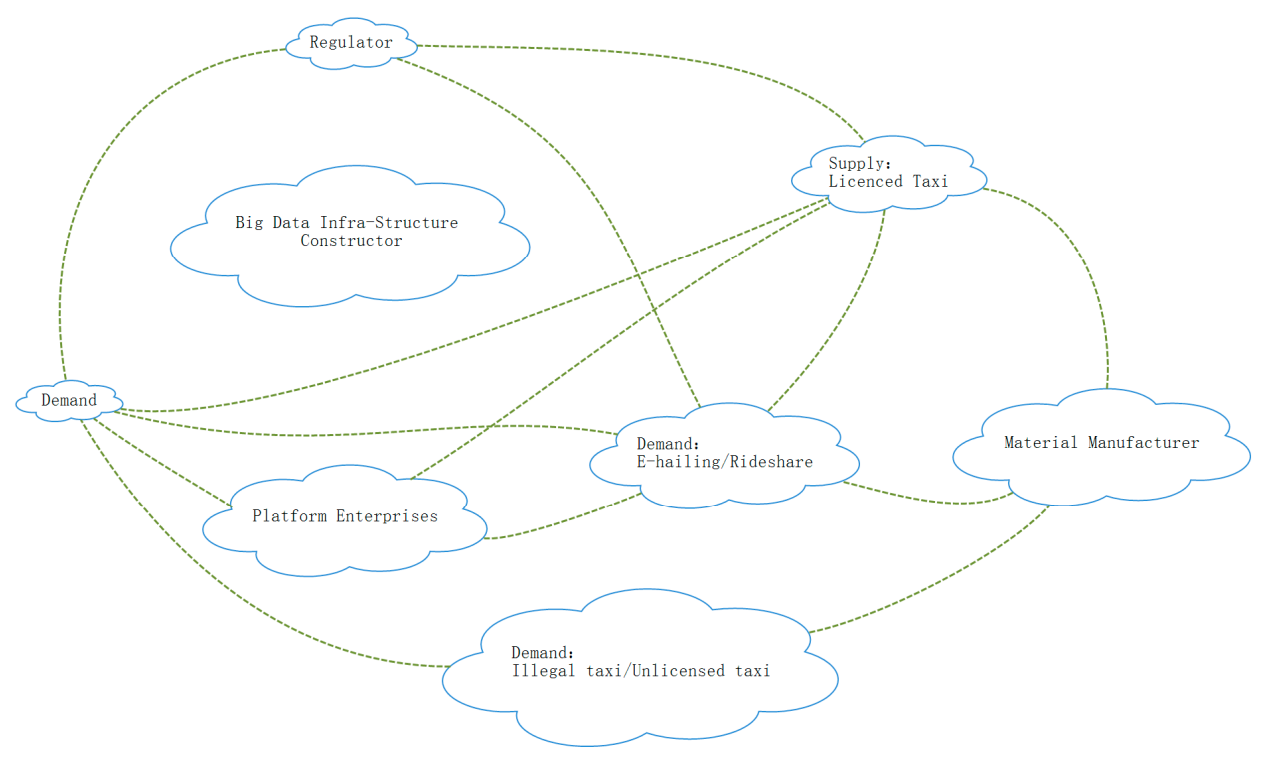

Figure 1. Urban Taxi Ecosystem.

Citizens are able to select taxi or e-hailing via platform apps. Regulators who are citizens on the demand side, taxis and e-hailing, which are on the supply side, and platform enterprises, establish a fundamental part of the ecosystem. IoT and Big Data infrastructure provide efficient data exchanges. With the increasing car-use demands, the number of new energy vehicles sold by the first quarter in 2018 was 13,192 units, which was a $179.6 \%$ increase over the same time last year. Hence, the illegal taxis have been squeezed out of the urban taxi market, which saves the cost of government's enforcement.

As a new community of urban taxi ecology, e-hailing has been developed to supplement the supplies of urban taxis. Issue No. 58 (2016) by General office of the state council "The General Office of The State Council Gives Guidance On Deepening Reform \& Promoting The Healthy Development Of The Taxi Industry" [9] and Issue No. 48 by Shanghai Government "Regulations On The Management Of E-hailing Services In Shanghai" [10] indicate the legal status of online car-hailing service in China. Cruising taxi drivers who were employed by taxi service enterprises need to accept qualification training and performance management. The taxi service enterprises need to pay a lot of operation and management costs. E-hailing on the supply side has a much lower entry cost that omits driver training and performance managements, and provides no social fringe benefits or insurance. Private car owners are compensated for a flexible form of participation in the taxi industry.

The method of working attracts more and more car owners to join in the e-hailing community, which has had a strong substitution effect on the illegal taxi community. Compared with the non-uniform standard of fee rate and the driver's credit, e-hailing responses to users' demand is immediate and reachable, adopts a unified credit system that binds both passengers' and drivers' breaches of service agreement, and uses a standard price rate system. This makes it is more reliable for users to make customized trips on the car-hailing platform. Black car (illegal taxi) drivers are more willing to join the e-hailing platform (community) to get more stable customer orders. E-hailing is naturally a strong substitution for illegal taxis. As a result of this substitution effect, the contraction of the illegal taxi community has saved the government's input in the regulation of black cars. Restrictions on vehicle emissions and wheelbases in regional implementation rules 
support the public demand for clean energy vehicles. This consumes the capacity of for the new energy automobile industry from the demand side. The demand pulls the development of the new energy automobile industry.

\section{E-Hailing Rent-Seeking Behavior}

The concept of rent-seeking was first developed by Tullock [11], while the precise term was suggested by Krueger [12]. Economic rent was discussed by Posner under the monopoly and governmental regulation view [13]. The rent-seeking theory holds that power owners set and use policies to restrict market supply, and thus they create scarcity in order to gain unproductive profits (so called economic rent). Individuals then exploit their privileges, and (legally or illegally) search for and occupy these economic rents (rent-seeking) [12]. Most discussions about rent-seeking theory were based on angles that governments used of public power to set or seek rent, or based on governmental rent-setting, interest groups bribery, and public power corruption. Most research suggest that paying well eliminates corruption and punishment on government public power rent-seeking. However, the purpose of e-hailing's entry into China's taxi industry was to introducing competition and to improving the travel efficiency of citizens. Therefore, it is doubtful that government rent-seeking and collusion is present here. It is obvious that traditional rent-seeking theory has its limitations in studying China's contemporary taxi industry. The phenomena such as red-pack and subsidy wars, price wars, taxi strikes and cross-platform order taking cannot be explained by traditional rent-seeking theory. This paper tries to explain these problems from the angle of the extrusion of government public power by the capital power of Internet enterprises.

\subsection{Rent-Seeking Behavior of E-Hailing Platform Enterprises}

Most rent-seeking research is based on the premise that the government holds the public power to carry out rent-seeking activities. Those studies also assume that enterprises gain profit by maintaining monopoly. A government stands for the agency of the public. The government's rent-seeking behavior jeopardizes the public interest. Property dilution theory [14] holds that the private property of citizens is not always private, because when citizens are engaged in social activities, private property is always partially placed in the public domain to form public property. As the agent of public interest, government agencies are entrusted by the public to manage public property.

In the car-hailing scene, the public will connect their own vehicles (private property) to the online taxi ordering platform for "sharing", which corresponds to the idea of the public property from the property dilution theory. As an agent, enterprises on the ride-hailing platform directly participate in the resource allocation activities of public property by providing platform information interactive services. The government is in the position to supervise the competition and cooperation mechanism between e-hailing enterprises and traditional taxi enterprises. Due to the nature of the state-owned capital of traditional taxi companies, governments naturally impose more regulations on traditional taxi companies. However, e-hailing platform enterprises are mostly private owned companies. The shareholders may consist of multiple venture capital investors. The taxi service is a fundamental operation that carries out other commercial purposes. The enterprise's strategic and business objectives are plural. It is difficult for the government to directly manage such enterprises.

Urban taxi drivers and passengers are regarded as independent rational economic individuals. Drivers perceive utility through their operating income. The number of car-hailing users in China reached 287 million in 2017, a growth rate of 27.5\% compared with 2016 [15]. Assuming that the total population base remains the same, the growth of e-hailing users must come from the traditional taxi user group and the illegal taxi user group. Since the increase in user size is a result of matching between the supply and demand sides, the growth of the community size of the users of e-hailing is bound to be accompanied by the synchronous growth of the community size of the car-hailing drivers. For the sake of simplification, it is assumed that the size of the black car market has been shrinking to a negligible state. For passengers, the network has the same purpose as the traditional taxi, which is to carry 
passengers from the place of departure to the destination. Thus, the utility objective function of the passenger is $\mathrm{U}=\mathrm{f}(\mathrm{u} 1, \mathrm{u} 2), \mathrm{U}$ represents the utility function value of the passenger, and $\mathrm{U} 1$ indicates the utility of traditional taxis for passengers (less travel time than public transportation), and U2 indicates that the e-hailing taxi is carrying the utility of a car to the passenger (less travel time than the public transport). Furthermore, it is assumed that, in general, a vehicle can carry passengers to the destination faster than the public transportation tools, and that the passengers save time from the same journey. This factor is $x$. It is found that the physical and functional properties of the traditional taxis and e-hailing are both cars, which can achieve the same effect for the passengers. The passenger's utility function can be further expressed as $\mathrm{U}=\mathrm{f}(\mathrm{u} 1(\mathrm{x}), \mathrm{u} 2(\mathrm{x}))$. Assuming that passengers have disposable income at any time and that they can consider one of the two ways of choosing traditional taxis and networks, then at all times, the passenger's choice is a budget constraint. When the total disposable income used for the consumption of traditional taxis is a units, and the total disposable income used for the consumption of e-hailing is $b$ units, the budget constraint line can be expressed as: $y=-(b / a) x+b$. Corresponding to the $(\mathrm{Q} 0, \mathrm{Q} 0)$ consumption mix, passengers' consumption portfolio in this case, is shown in Figure 2.

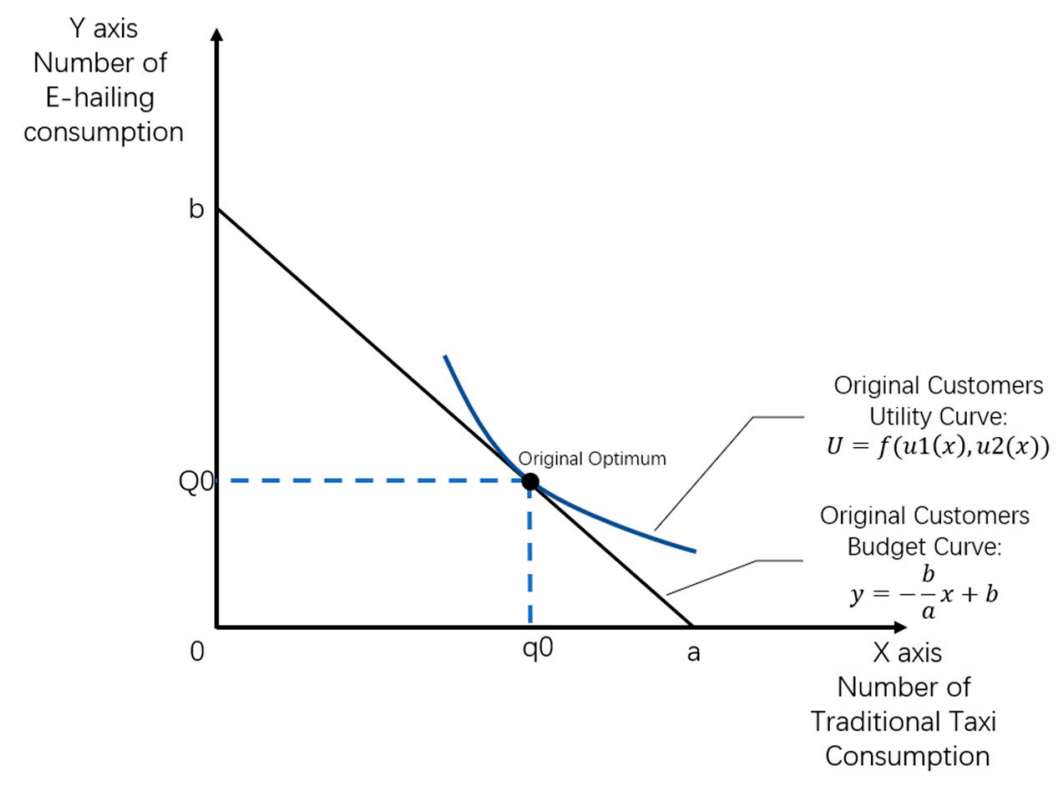

Figure 2. Passengers optimum consumption combination under "using taxi \& saving time" utility.

When the car-hailing platform enterprise implements the market strategy of red package and subsidy, it can be seen that the number of passengers consuming under a fixed budget increases; point $b$ rises to the point $b^{\prime}$, the passenger's budget constraint is changed to $y=-\left(b^{\prime} / a\right) x+b^{\prime}$, and the new utility curve of the passengers is changed to $\mathrm{U}^{\prime}=\mathrm{f}^{\prime}(\mathrm{u} 1(\mathrm{x}), \mathrm{u} 2(\mathrm{x}))$. The new optimum point corresponds to the consumption combination of (Q1, Q1), compared with the original Q0 (Q0). $\Delta \mathrm{q}=(\mathrm{q} 1-\mathrm{q} 0)<0$ is the reduction of traditional taxi consumption which is affected by the policy of red pack and subsidy by e-hailing companies. $\Delta \mathrm{Q}=(\mathrm{Q} 1-\mathrm{Q} 0)>0$ is an increase in e-hailing consumption stimulated by the red packets subsidy strategy of the platform (Figure 3).

Therefore, there is a basic conclusion that the urban taxi market is affected by the "red packets subsidy war" by the Internet platform enterprises:

Proposition 1. As the red packet subsidy market strategy substantially increases the number of passengers under their given budgets, the passenger's utility (indifference) curve has changed, and the passenger's consumption preference is more inclined to e-hailing cars, and the new optimum combination is derived from the income effect and the substitution effect of the red packet subsidy strategy. 


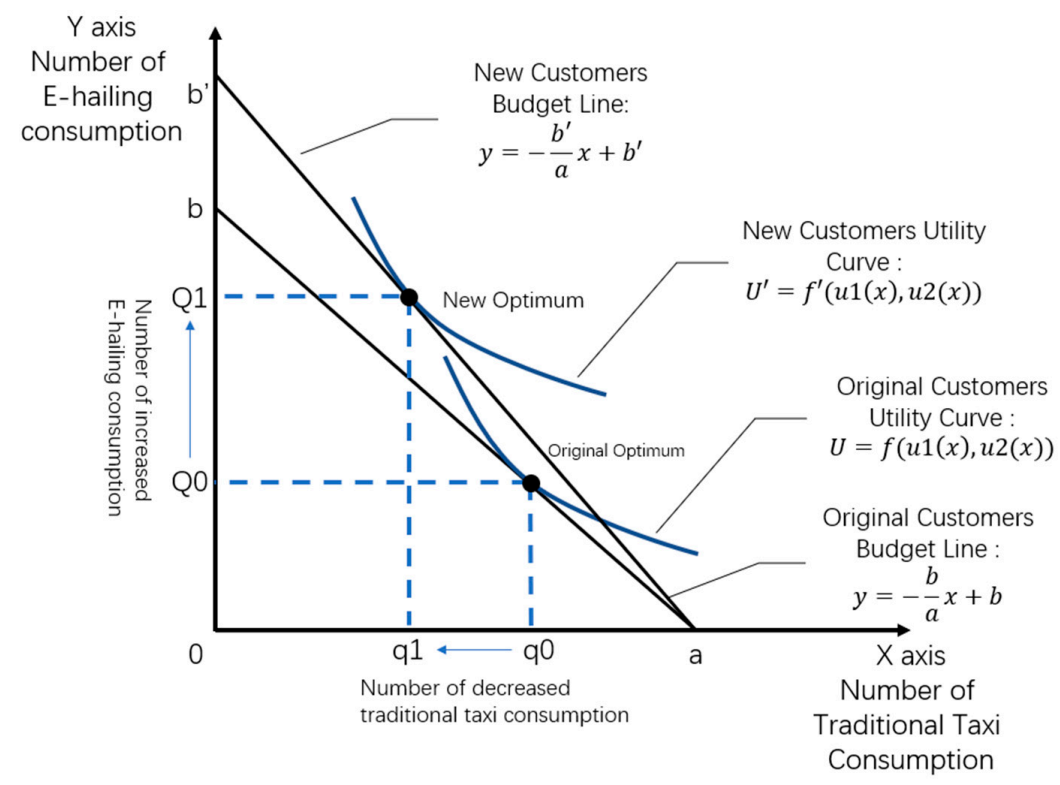

Figure 3. Passengers' consumption mix affected by the red packet \& subsidy strategy implemented by the e-hailing company.

Why are passengers willing to take more e-hailings? For the passengers themselves as consumers, they are economically rational, and under the same budget and equal utility, they always tend to consume cheaper goods, and so do taxis.

The red packet and subsidy strategy in Proposition 1 is only one of the factors. The second important factor is that there has been a significant change in the method of calling cars and settling fees. For example, e-hailing makes use of mobile equipment to access the Internet when it calls the idle vehicle resources. The efficiency of the call is improved. When the passenger uses their mobile equipment to pay the cost of the car, this avoids the risk of counterfeit cash payment, saves the time of payment, and improves the efficiency of the car driver's receipt and increases order efficiency. Assuming that the time saving utility factor of the ordering and settlement method is $y$, and the passenger utility level function is $U^{\prime \prime}=f^{\prime \prime}(\mathrm{u} 1(\mathrm{x}), \mathrm{u} 2(\mathrm{x}, \mathrm{y})), \mathrm{u} 1$ expresses the utility of traditional taxis for passengers, and $\mathrm{u} 2$ indicates that the e-hailing is carrying the utility of the passengers, and factor $x$ indicates that the passenger uses a taxi to obtain the time consuming factors under the same way than the public transportation. Factor y expresses the time saving utility factor of the e-hailing and the settlement. Obviously, $y$ is unique to e-hailing.

According to the principle of market clearing [13], assuming that the actual price changes caused by the e-hailing subsidy, etc., can always quickly bring the supply and demand sides into a new equilibrium, then passengers in the new optimum combination (q1, Q1) will have a corresponding combination of supply in the taxi market. The change in the supply and demand sides of the e-hailing community is actually a combination of supply and demand changes. The red packet subsidy strategy of the online vehicle platform company targets both the car driver and passengers at the same time, resulting in an increase in the purchasing power of passengers. Thus, the demand curve moves to the outside. More private car owners become e-hailing car drivers, and the supply curve also moves to the outside. The supply curve and demand curve of the online car market moves to the outside at the same time, resulting in an increase in car hailing consumption increase in Q1-Q0 (as point Q0 moves to Q1). At the same time, the consumer price P1 may still be close to the original level, or even lower, due to the existence of red pack and subsidies (Figure 4). 


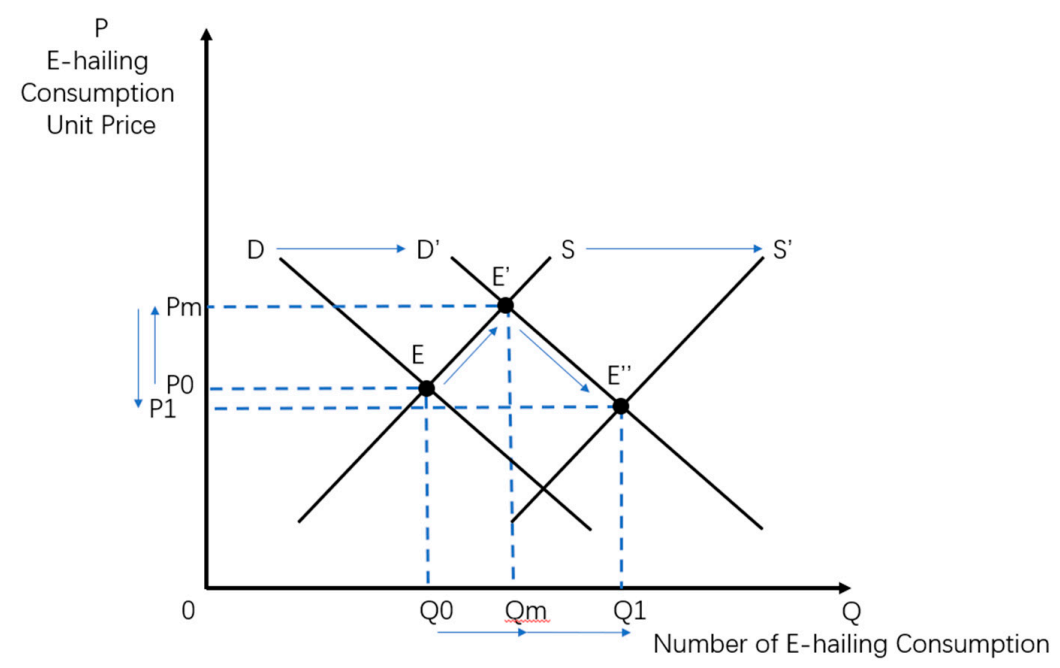

Figure 4. The changes of supply and demand balance of network vehicle community under the Red Packet subsidy strategy.

As a supplier, the increase in the number of e-hailing car drivers at the same time comes from the owners of private cars and traditional taxi drivers. Traditional taxi drivers use taxis (corporate assets) to engage in e-hailing operations, which is a type of free rider [14] act, because traditional taxi drivers drive a taxi, and the means and goals of their income changes, the size of the traditional taxi community actually shrinks (Figure 5).

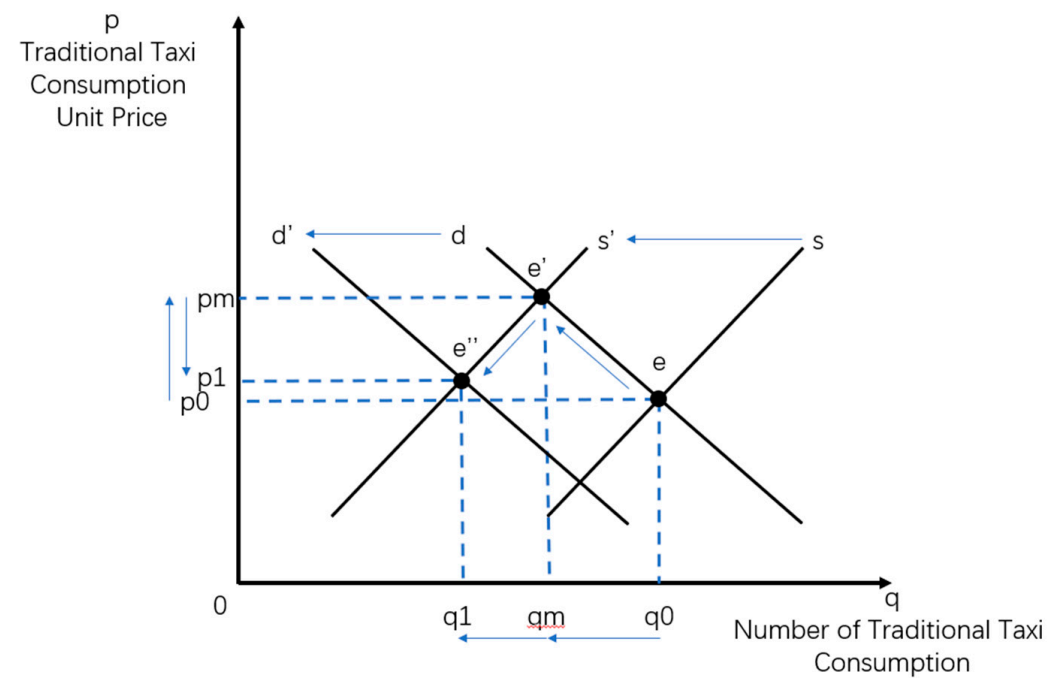

Figure 5. The changes of supply and demand balance of traditional taxi communities under the Red Packet subsidy strategy.

Therefore, we have obtained the following basic conclusion about the relationship between supply and demand in the taxi market under the red pack and subsidy strategy:

Proposition 2. The red packet $\&$ subsidy strategy of the e-hailing platform company increases the number of passengers on the platform and the number of car drivers at the same time, that is, the scale of the ecological community of the e-hailing vehicles increases, which accompanies the shrinking of the ecological scale of traditional taxis. 
The composition of the ecological community in China's traditional taxi industry is diverse. Traditional taxis are cruising cars, and the ownership structure of cruising car companies is mostly state-owned or mixed, which lies directly under the supervision and assessment by the Ministry of Transport of the People's Republic of China (PRC).

The shrinking of the ecological community of traditional taxis (cruising cars) has reduced the scope of supervision of the Ministry of Transport of PRC. The ownership structure of the e-hailing platform company is composed of multi-participant investors. The capital participates in public activities through such Internet platform enterprises. The influence of capital on public social activities expands with the expansion of the ecological community scale of the e-hailing vehicle. Under this premise, the public power in the Property Dilution Theory [14] — the government, as an attorney of public property, experiences the unequal changes in the agency's responsibilities and the agency scope. Even if its agency responsibilities remain unchanged, the scope has become smaller as the traditional taxi community shrinks. In the eco-community of the e-hailing, the Internet platform company has become the agent of public property, and the client is the public-private car owner. The venture capital behind platform companies is inherently profit seeking, and lacks active supervision of the public's private property in the public domain. At the same time, the public's personal supervision of the public power of platform companies has inherent innateness and a lack of regulatory means. The logic of collective behavior [16,17] believes that when management and incentives are carried out in large public groups, taking into account the principle of the economic rationality man, government supervision is carried out by natural persons, which will inevitably lead to free riders and moral risks. Venture capital investors also have this characteristic. As a result, it is concluded that the agency responsibility of the e-hailing platform company is:

Proposition 3. With the expansion of the size of the e-hailing community, the e-hailing vehicle platform enterprise has replaced the government's supervisory responsibilities to a certain extent, while the venture capital investor, as a rational economic person, has a natural contradictions in its agency responsibility and its profit-seeking.

\subsection{The Capital's Rent-Seeking Behavior through the Business Model}

Venture capital uses Internet platform companies to express their own needs for commercial interests, while commercial interests challenge the bottom line of social morality. Venture capital owners have the possibility of distorting their representative public power for their own interests. Venture capital through e-hailing platform companies provides the public e-hailing ordering service-this new type of sharing economic business model, by means of red packet \& subsidy strategies to quickly gain market share and establish the industry monopoly, public recognition and acceptance, which leads to the conclusion of the venture capital rent seeking behavior:

Proposition 4. Venture capital through e-hailing platform companies (reasonable extrapolation to: Internet platform companies) to promote the emerging business model and obtain market monopoly position, essentially a rent-seeking behavior. Different from the government's setting up rent, the rent-seeking of capital is achieved through the business model by obtaining market monopoly status.

Capital rent-setting is also a non-productive activity in which a capital uses its power as a bargaining chip to gain its own interests. Traditional public power rent-setting behavior means that the government uses its public power to gain market monopoly status and seeks profits, while capital rent-setting is a venture capital investor using a business model to obtain market monopoly status and to obtain the approval of the government and the public; because the business model usually identifies the pain points of the user group, its utility level is often higher than the government's mandatory regulatory policy. Citizens, acting on the assumption of the rational economic man, eager for the utility increment, and participate in the business model. The government hopes to supervise, and is 
often forced to enter into the business model scenario. This is called "user abducted" by capital and "government abducted" phenomenon. The public's willingness to seek rent through the collective increase in the size of the group to become collective rent-seeking [18] does not hold true in this venture capital-driven emerging business model scenario. Therefore, there is a conclusion about capital rent-setting:

Proposition 5. The (venture) capital rent-setting behavior forces both the public and the government to participate in it. The behavior attracts the public to gain market monopoly status through the business model's own profit-seeking, and then set rent through this status, which creates conflict, substitution, and bargaining. It is an inevitable result of the development of a certain scale effect through commercial behavior.

\subsection{Capital Rent-Seeking and the Utility of Exercising Public Power}

Although the capital and the government exist for different purposes and they have different essential meanings, the ways to obtain market status are also different. However, what the two have in common is that they may also seek benefits for themselves while shouldering the duties of public power.

Assume that the utility function of capital in the use of Internet platform companies (e.g., Internet car-hailing platform companies) to participate in public power is:

$$
\mathrm{Uv}=\mathrm{g}(\alpha, \beta)
$$

Uv is the utility of capital's public power, $\alpha$ represents the use of platform companies and business models to disseminate benefits for themselves; $\beta$ represents the benefits created by the use of platform companies and business models for public interests.

$(\partial \mathrm{Uv}) / \partial \alpha>0$ represents the positive correlation between the benefits of the use of an Internet platform business and a business model for capital, and its own utility level. ( $\partial \mathrm{Uv}) / \partial \beta<0$ represents the negative correlation between the benefits of the capital utilization of Internet platform companies and business models for the public and their own utility levels.

The expansion of the size of the community of users and drivers of e-hailing, and the reduction in the size of traditional taxi users and drivers heralds the success of capital rent-seeking and rent-setting. The utility function and balance between the supply and demand of users and drivers in the taxi ecological community are market responses to capital rent-seeking behavior. It is clear that the utility function of capital has also changed:

$$
\mathrm{U}^{\prime} \mathrm{v}=\mathrm{g}\left(\alpha^{\prime}, \beta^{\prime}\right)
$$

$\alpha^{\prime}>\alpha$ indicates that the interest gained after capital rent seeking is higher than that before rent seeking; $\beta^{\prime}<\beta$ indicates that the benefits to the public after capital rent seeking are less than those created before rent seeking. The interests of the Internet platform companies controlled by capital (such as the e-hailing platform company) create for themselves. There are both mutual benefits under cooperative games, and there are also public interest eliminations and capital gains under the zero-sum game.

$\beta^{\prime}<\beta$ results in the mixed interest combination. It is difficult for the public to dismiss the capital (which representing e-hailing enterprises) even if it discovers that the exercise of its public power by the capital impairs the interests of the public (public information privacy, public information security). This is because at the time being, the public has widely accepted and recognized the benefits of the business model provided by the capital, and every individual in the public has different perceptions of the difference in interest of $\left(\beta^{\prime}-\beta\right)$. There is a steep increase in the likelihood that individuals will not be able to reach agreement.

Therefore, we reach the following conclusion about rent-seeking by capital utilizing platform companies: 
Proposition 6. (Venture) Capital makes use of Internet platform companies to set rent and to create benefits for themselves. Because the capital of commercial companies lies between the government and the public, and it partly replaces the government's public powers, the public creates capital for the public in accepting capital. While accepting the benefits created by capital, the public does not have the ability to strictly divide the boundaries of public interests that are damaged by capital. The public's "force" to supervise the capital of enterprise representatives is dispersed.

When capital realizes that the "collaborative force" of the public over its supervision is weak, capital may increase its infringement on the public interest. It is natural that the government needs to supervise the capital behind the business model. Traditional research on rent-seeking behavior believes that high-paying eliminates corruption $[19,20]$ is able to stimulate the government to provide better service to the public. Once the (venture) capital is between the government and the public and assumes the role of some public power, even if the high-paying eliminates corruption, the policy is for (venture) capital, and there is no practical value. The reason is that capital does not lack a "high salary". High-level managers of Internet platform enterprises representing capital owners also do not lack "high salary". Therefore, supervision has entered a "vacuum" at the level of such business organizations.

\section{Conclusions}

It is due to the fact that "salary" has zero marginal utility to capital and business executives, that there is no "high-paying to eliminate corruption" method in the governance of a capital that relies on e-hailing platforms (such Internet platform enterprises).

Introducing competition is a means of breaking the monopoly of market policies. When the government usually introduces competitors, both the competitors and the original market monopolist are commercial capitals. Both parties may form cartels and business alliances through the exchange of competitive information. Even though the government may adopt anti-monopoly laws to restrict business alliances, both parties to the competition can also evade laws or policy regulations through commercial mergers or implementation protocol control agreements, i.e., VIE (Variable Interest Entities).

When the user community of a e-hailing platform enterprise grows larger than the size of the traditional taxi user community, it often signals the success of this specific sharing economy business model. However, it is difficult for the public to have highly uniform and specialized knowledge, so the government should try to actively participate in the governance of such organizations.

The government departments (for example, the Ministry of Transport) have the most commonly used method of interviewing companies on the Internet platform, but this kind of method has only played an administrative role. Internet platform companies often have public privacy data, while the government often knows nothing about how enterprises use the data. If government can supervise the data and establish a mechanism for auditing and reviewing these public data owned by Internet platform companies, it will impose a good restriction on the ethical issues of the use of public privacy data by those companies.

Secondly, in the stage of refinancing by such enterprises, the government tries to enter into the equity structure of such enterprises through tender offers, open market stock purchase, or the use of securities in exchange for stock shares in the company, which gains relative control and balances commercial interests and business ethics in the capacity of shareholders.

Author Contributions: L.M., T.L., J.W. and D.Y. made the Conceptualization of the paper together; T.L. wrote the original draft, visualized figures and editing review and final proofreading; L.M. helped collect cases and data during the writing and made suggestions to the paper suitable to the journal scope. T.L. worked as a correspondence author for the study.

Funding: The publishing fee of this paper was supported by the DGIST R\&D Program of the Ministry of Science, Technology and ICT (DGIST-18-IT-01).

Conflicts of Interest: The authors declare no conflict of interest. 


\section{References}

1. Yun, J.H.J. How do we conquer the growth limits of capitalism? Schumpeterian Dynamics of Open Innovation. J. Open Innov. Technol. Mark. Complex. 2015, 1, 17. [CrossRef]

2. Yun, J.H.J.; Won, D.K.; Park, K. Dynamics from open innovation to evolutionary change. J. Open Innov. Technol. Mark. Complex. 2016, 2, 7. [CrossRef]

3. Yun, J.H.J. Economic Effects of Open Innovation. J. Innov. Knowl. 2018. [CrossRef]

4. Yun, J.J.; Won, D.; Jeong, E.; Park, K.; Lee, D.; Yigitcanlar, T. Dismantling of the Inverted U-Curve of Open Innovation. Sustainability 2017, 9, 1423. [CrossRef]

5. Yun, J.J.; Won, D.; Park, K.; Yang, J.; Zhao, X. Growth of a platform business model as an entrepreneurial ecosystem and its effects on regional development. Eur. Plan. Stud. 2017, 25, 805-826. [CrossRef]

6. Yun, J.J.; Won, D.; Hwang, B.; Kang, J.; Kim, D. Analysing and simulating the effects of open innovation policies: Application of the results to Cambodia. Sci. Public Policy 2015, 42, 743-760. [CrossRef]

7. Lampard, E.E. City. Available online: https://www.britannica.com/topic/city (accessed on 20 September 2017).

8. Britannica. Taxicab. Available online: https://www.britannica.com/technology/taxicab (accessed on 14 July 2017).

9. General Osteopathic Council (GOSC). The General Office of the State Council Gives Guidance on Deepening Reform \& Promoting the Healthy Development of the Taxi Industry. Available online: http:/ /www.gov.cn/ zhengce/content/2016-07/28/content_5095567.htm (accessed on 26 July 2016).

10. SHMPG. Regulations on the Management of Car-Hailing Services in Shanghai (Issue No. 48). Available online: http:/ / www.shanghai.gov.cn/nw2/nw2314/nw2319/nw12344/u26aw50666.html (accessed on 21 December 2016).

11. Tullock, G. The welfare costs of tariffs, monopolies, and theft. Econ. Inquiry 1967, 5, 224-232. [CrossRef]

12. Krueger, A.O. The Political Economy of the Rent-Seeking Society. Am. Econ. Rev. 1974, 64, 291-303.

13. Posner, R.A. The Social Costs of Monopoly and Regulation. J. Polit. Econ. 1975, 83, 807-827. [CrossRef]

14. Barzel, Y. Economic Analysis of Property Rights; Cambridge University Press: Cambridge, UK, 1997; pp. 147-179.

15. CNECRC. The Number of Taxi Users in China's E-Hailing Reached 287 Million in 2017. Available online: http:/ / www.ec100.cn/detail--6436253.html (accessed on 28 February 2018).

16. Say, J.B. A Treatise on Political Economy; or the Production, Distribution, and Consumption of Wealth. Soc. Sci. Electr. Publ. 2009, 136, 199.

17. Olson, M. The Logic of Collective Action: Public Goods and the Theory of Groups; Harvard University Press: Cambridge, MA, USA, 1971.

18. Fu, J. Power Structure, Group Scale and Collective Rent-seeking. Econ. Sci. 2004, 26, 18-26.

19. Becker, G.; Stigler, G.J. Law Enforcement, Malfeasance, and the Compensation of Enforcers. J. Legal Stud. 1974, 3, 1-18. [CrossRef]

20. Banfield, E.C. Corruption as a Feature of Governmental Organization. J. Law Econ. 1975, 18, 611-615. [CrossRef]

(C) 2018 by the authors. Licensee MDPI, Basel, Switzerland. This article is an open access article distributed under the terms and conditions of the Creative Commons Attribution (CC BY) license (http://creativecommons.org/licenses/by/4.0/). 